\title{
A cross sectional study to evaluate the relation between thyroid disorders and abnormal uterine bleeding in reproductive age group
}

\author{
Kirti Verma ${ }^{1^{*}}$, Suniti Verma ${ }^{2}$, Lata Rajoria ${ }^{3}$ \\ ${ }^{1}$ Post Graduate Student, ${ }^{2}$ Professor and Unit Head, ${ }^{3}$ Senior Professor and Head, ${ }^{1-3}$ Dept. of Obstetrics and Gynecology, Sawai Man Singh \\ Medical College, Jaipur, Rajasthan, India \\ *Corresponding Author: Kirti Verma \\ Email: kirtiverma118@gmail.com
}

Received: $31^{\text {st }}$ January, 2019

Accepted: $2^{\text {nd }}$ May, 2019

\begin{abstract}
Introduction: Abnormal uterine bleeding (AUB) is a common disorder occurring in reproductive age group females. It can be understood as bleeding that occurs from the uterus outside the normal parameters and there is no structural defects in the genital tract. One of the most common association with AUB is thyroid dysfunctions. Hence this study aimed to see the incidence of thyroid related disorders in AUB and also to assess the menstrual pattern.

Material and Methods: 100 women suffering from AUB who presented to OPD of Gynecology department of SMS Medical College, Jaipur were recruited in the study. All females in 19 to 45 years of age group with abnormal uterine bleeding were included excluding those with previously known thyroid disorder, abortion history within 3 months etc. Thyroid function tests were done in all along with ultrasonography of pelvis region. Statistical analysis done.

Results: The bleeding abnormality that was found in the most of the women was heavy menstrual bleeding. Women who presented with thyroid dysfunction were 33\%. 23\% had subclinical hypothyroidism, 6\% had hypothyroidism and 4\% had hyperthyroidism.

Conclusion: Abnormal Uterine Bleeding has strong association with thyroid disorders. Most common type of disorder is subclinical hypothyroidism. Thus all patient of AUB must be evaluated for thyroid dysfunction
\end{abstract}

Keywords: Abnormal uterine bleeding, Subclinical hypothyroidism.

\section{Introduction}

Abnormal Uterine Bleeding (AUB) means any bleeding that is not normal in amount, duration, frequency and cyclicity. ${ }^{1}$ AUB is very common as well as a complicated presentation in gynaecology outpatient department. It is seen in $15-20 \%$ of women from the commencement of menarche to menopause and have great impact on quality life of the women. ${ }^{2}$ Failure in finding etiology along with debilitating symptoms mostly results in unnecessary surgical interventions causing increase in morbidity and mortality. Endocrinological dysfunctions including thyroid disorders plays major role in its etiopathogenesis. Thyroid hormones exerts multiple effects on the human body specifically on the development,metabolism, growth and functions of major organ system in the human body. ${ }^{3}$ Looking to its effects on reproductive age group females, thyroid dysfunction leads to AUB, infertility, delayed puberty recurrent miscarriages as well as premature menopause. ${ }^{4}$

Mechanism behind menstrual irregularities due to thyroid disorders are multiple. Some of these are like, alterations in TSH response, altered $\mathrm{LH}$ response and conversion of androgens to estrogen peripherally, TRH causing increased prolactin levels, altered SHBG and effect on the coagulation factors. 5,6

Irregularities in the menstrual cycle may accompany or precede with clinically overt hypothyroidism or hyperthyroidism. ${ }^{7}$ Many studies have proven that hypothyroidism is more commonly associated with hypothyroidism whereas anovulation or oligomenorrhoea common in those having hyperthyroidism. ${ }^{8,9}$
This study was done to evaluate the thyroid dysfunction in patients with AUB and to find out the incidence of thyroid disorders in AUB patient and also to study the menstrual pattern in thyroid disorders.

\section{Material and Methods}

It was a hospital based cross sectional descriptive type of observational study conducted in the department of Obstetrics and Gynaecology, SMS Medical College and Attached hospitals, Jaipur from April 2017 to April 2018. 100 women who presented to gynaecology outpatient department with AUB were recruited in the study.

\section{Inclusion Criteria}

1. All females in 19 to 45 years of age group with abnormal uterine bleeding and those giving informed consent were included as subjects in proposed study.

\section{Exclusion Criteria}

1. Patients with previously known thyroid disorder

2. Abortion history within 3 months

3. History of childbirth within 1 year

4. IUCD /OC pill users

5. Patients with known liver disorders or coagulopathy

6. Known cases of cancer of genital organs

7. Known cases of autoimmune disorders

8. Diagnosed cases of uterine fibroid, polyps, ovarian cyst, endometriosis, polycystic ovarian disease, malignancy, cervical tumors 
Continuous variables were summarized as mean and standard deviation whereas nominal/categorical variables as proportions. Parametric tests like ANOVA test was used for continuous variables while chi-square test was used to analyses nominal/categorical variables. $\mathrm{P}$ value $<0.05$ was taken as significant. Medcalc 16.4 version software was used for all statistical calculation.

\section{Results}

A total of 100 patients in reproductive age group with AUB were recruited in the present study. Among 100 women, majority belonged to the age group between 30 to 39 years (39\%) and least of them belonged to less than 20years age group. $35 \%$ were between age group of $20-29$ years and $21 \%$ were above 40 years of age. (Fig. 1)

Commonest pattern of bleeding was heavy menstrual bleeding $(45 \%)$ followed by heavy menstrual bleeding with frequent cycles (16\%). Among others $15 \%$ presented with infrequent cycles, $11 \%$ had acyclical bleeding, $8 \%$ with frequent cycles and 5\% with shortened cycles. (Table 1)

Among thyroid dysfunction, majority of the women belonged to category of subclinical hypothyroid (23\%).Among others $6 \%$ were hypothyroid and $4 \%$ were hyperthyroid. (Fig. 2)

Thyroid dysfunction is related to various types of bleeding abnormalities. Thyroid dysfunction was commonest in patients with acyclical bleeding $(63.63 \%)$, the next common in women with infrequent cycles $(40 \%)$. $37.5 \%$ of women with frequent cycles, $26.66 \%$ of women with heavy menstrual bleeding and $25 \%$ of women with heavy menstrual bleeding with frequent cycles were with thyroid dysfunction. (Table 2)

Table 1: Distribution of study subjects according to bleeding patterns

\begin{tabular}{|l|c|c|}
\hline \multicolumn{1}{|c|}{ Type of bleeding } & N & \% \\
\hline Shortened Cycles & 05 & 05 \\
\hline Frequent Cycles & 08 & 08 \\
\hline Acyclical & 11 & 11 \\
\hline Infrequent Cycles & 15 & 15 \\
\hline HMB with frequent cycles & 16 & 16 \\
\hline Heavy Menstrual bleeding & 45 & 45 \\
\hline \multicolumn{1}{|c|}{ Total } & 100 & 100 \\
\hline
\end{tabular}

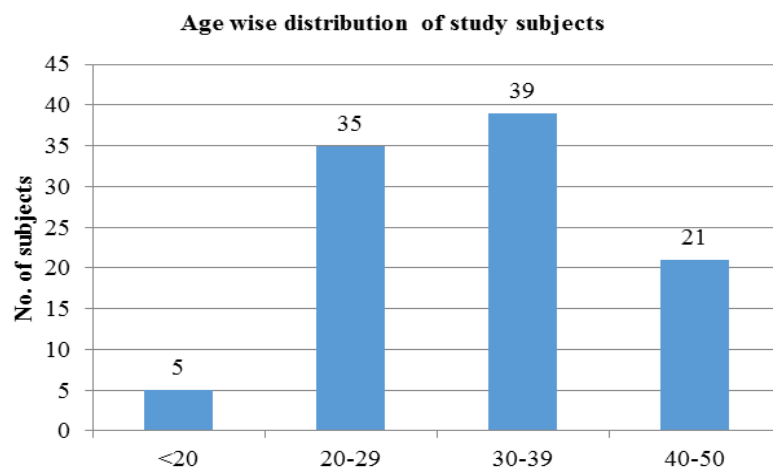

Fig. 1: Age wise distribution of study subjects Thyroid status of study subjects

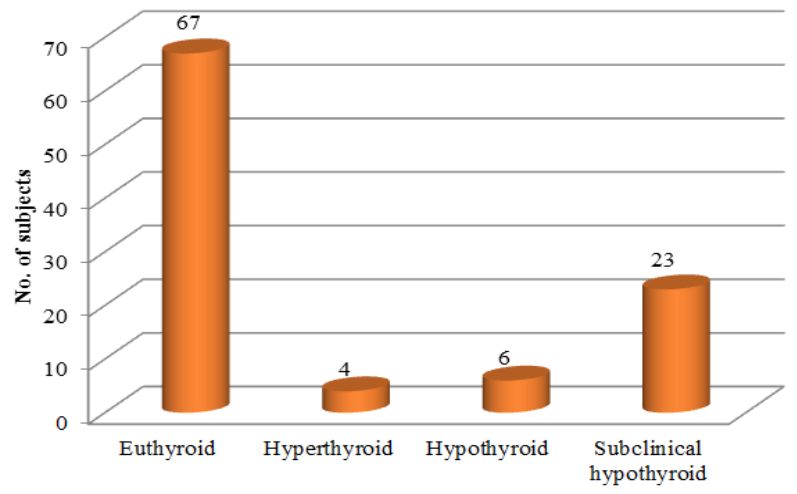

Fig. 2: Distribution of study subjects according to thyroid status

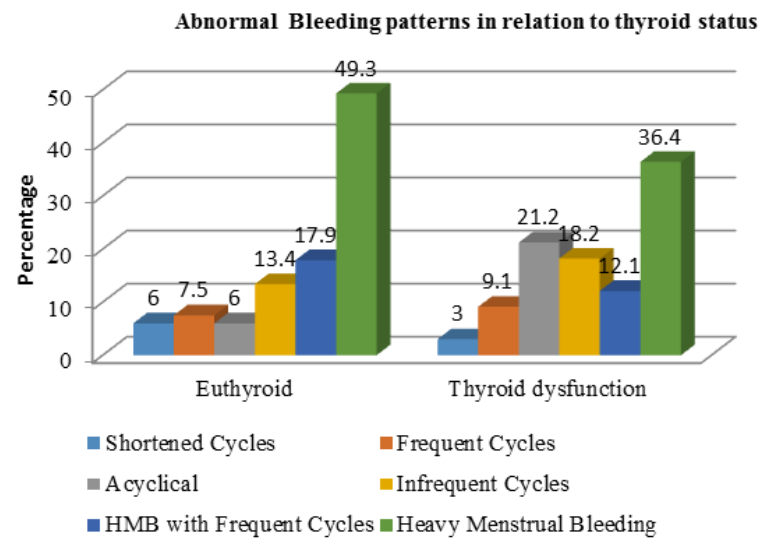

Fig. 3: Abnormal Bleeding patterns in relation to different thyroid status

Table 2: Abnormal Bleeding patterns in relation to different thyroid status

\begin{tabular}{|c|c|c|c|c|c|c|c|c|c|}
\hline \multirow[t]{2}{*}{ Type of bleeding } & \multicolumn{2}{|c|}{ Euthyroid } & \multicolumn{2}{|c|}{ Hyperthyroid } & \multicolumn{2}{|c|}{ Hypothyroid } & \multicolumn{2}{|c|}{$\begin{array}{c}\text { Subclinical } \\
\text { hypothyroid }\end{array}$} & \multirow[t]{2}{*}{ Total } \\
\hline & $\mathbf{N}$ & $\%$ & $\mathbf{N}$ & $\%$ & $\mathbf{N}$ & $\%$ & $\mathbf{N}$ & $\%$ & \\
\hline Shortened Cycles & 04 & 80 & 00 & 0 & 01 & 20 & 00 & 0 & 5 \\
\hline Frequent Cycles & 05 & 62.5 & 00 & 0 & 00 & 0 & 03 & 37.5 & 8 \\
\hline Acyclical & 04 & 36.36 & 01 & 9.09 & 02 & 18.18 & 04 & 36.36 & 11 \\
\hline Infrequent Cycles & 09 & 60 & 02 & 13.33 & 01 & 6.66 & 03 & 20 & 15 \\
\hline HMB with frequent cycles & 12 & 75 & 00 & 0 & 00 & 0 & 04 & 25 & 16 \\
\hline Heavy Menstrual bleeding & 33 & 73.33 & 01 & 2.22 & 02 & 4.44 & 09 & 20 & 45 \\
\hline Total & 67 & & 04 & & 06 & & 23 & & \\
\hline
\end{tabular}




\section{Discussion}

Thyroid disorders are common in females with subclinical hypothyroidism as its most common type. Menstrual irregularities are seen in both hyperthyroidism as well as hypothyroidism.

In the study most of the women were in the age group 30-39 years. Similar study done by Mohapatra $S$ et $\mathrm{al}^{10}$ reported that highest incidence of AUB was seen in the age group 30-39 years (39\%). Parveen M ET al ${ }^{11}$ also observed that majority of the women were in the age group between $30-39$ years $(44 \%)$. Similar results were in the study by Ali J ET al, ${ }^{12}$ Jinger SK et al ${ }^{13}$ and George L et al. ${ }^{14} 45 \%$ of women presented with complaint of heavy menstrual bleeding making it the most common pattern of AUB. It was followed by heavy menstrual bleeding with frequent cycles which was seen in $16 \%$ of women. Parveen $\mathrm{M}$ et al ${ }^{11}$ also found an incidence of $45 \%$ of heavy menstrual bleeding in their study. In study by Ali $\mathrm{J}$ et $\mathrm{al}^{12}$ and Verma SK et al ${ }^{15}$ $42 \%$ and $47.5 \%$ presented with HMB respectively. Women with complaint of shortened cycles were $5 \%$ which was similar as in the study by Verma SK et $\mathrm{al}^{15}$ i.e. $3.5 \%$ and Parveen $\mathrm{M}$ et $\mathrm{al}^{11}$ i.e. $5 \%$.

We observed that $33 \%$ of cases were diagnosed with thyroid dysfunction constituting $23 \%$ of the cases with subclinical hypothyroidism, $6 \%$ of the cases with hypothyroidism and $4 \%$ of the cases with hyperthyroidism. In the present study majority of the women were euthyroid, followed by subclinical hypothyroid, hypothyroid and hyperthyroid in decreasing frequency. These results were consistent with the study of Mohapatra S et al, ${ }^{10}$ Parveen M et al. ${ }^{11}$ In this study amongst those with thyroid dysfunction, women with subclinical hypothyroidism $(69.69 \%)$ were greater than those with hypothyroidism $(18.18 \%)$. This was similar to results of the study by George L et al ${ }^{14}(55.90 \%$ subclinical hypothyroid and $10.1 \%$ hypothyroid) and Maria JD et $\mathrm{al}^{16}$ (66.40\% subclinical hypothyroid). In a study by Avasthi S et $\mathrm{al}^{17}$ hypothyroid women were $16.66 \%$ of total thyroid dysfunction similar to this study.

$49.3 \%$ of euthyroid women and $36.4 \%$ of women with thyroid dysfunction presented with HMB. These results were comparable to the results of the study done by Maria JD ET al ${ }^{16}$ who concluded that $45.83 \%$ of euthyroid and $41.4 \%$ of women with thyroid dysfunction complained of HMB. In our study most common type of menstrual abnormality in women with subclinical hypothyroidism was heavy menstrual bleeding (39\%). $25 \%$ of women with hyperthyroidism and $33 \%$ of women with hypothyroidism presented with heavy menstrual bleeding. In AUB patterns $63.63 \%$ of women with acyclical bleeding and $26.66 \%$ of patients with HMB were of thyroid dysfunction. Results were similar to study of Mohapatra S ET al, ${ }^{10}$ Parveen M ET $\mathrm{al}^{11}$ and Deshmukh PY ET al. ${ }^{18}$

\section{Conclusion}

Abnormal uterine bleeding is strongly associated with thyroid related disorders. Any abnormality in menstrual cycle can be a possible presenting symptom of thyroid disorders, thus thyroid functions tests must be evaluated in them. It can lead to early diagnosis as well as treatment preventing unnecessary surgical interventions.

\section{Acknowledgement}

The authors sincerely thank Dr. Amandeep Singh, Dr. Namita Verma, Dr. Surekha, Dr. Vaidehi, Dr. Chitra, Dr. Anant, and Dr. Gayatri for their valuable support and help.

\section{Funding: None.}

\section{Conflict of Interest: None.}

\section{References}

1. Devi J, Aziz N. Study of histopathological pattern of endometrium in abnormal uterine bleeding in the age group of 40-60 years. A study of 500 cases. Int J Med Sci Clinic In vent 2014;1:579-85.

2. Padubidri VG, Daftary SN. Shaw's Textbook of Gynecology. $16^{\text {th }}$ ed. USA: Elsevier Health Sciences; 2015: 335-348.

3. Olive D, Palter S. Reproductive physiology. In: Berek JS. (eds). Berek and Novak's Gynaecology. 14 $4^{\text {th }}$ edn. Philadelphia: Lipincott Williams and Wilkins Company; 2002:161-86.

4. Thomas R, Reid R L. Thyroid disease \& Reproductive dysfunctions, Obstet Gynaecol 1987;70:789-98.

5. Doufas AG, Mastorakos G. The hypothalamic - pituitarythyroid axis and the female reproductive system. Ann NY Acad Sci 2000;900:65-76.

6. Poppe K, Velkeniers B, Glinoer D. Thyroid disease and the female reproduction. Clin Endocrinol 2007;66(3):309-21

7. Gowri M, Radhika BH, Harshini V, Ramaiaha R, Role of thyroid function tests in women with abnormal uterine bleeding. Int J Reprod Contracept Obstet Gynecol 2014;3(1):54-7.

8. Poppe, K. \&Glinoer, D. Thyroid autoimmunity and hypothyroidism before and during pregnancy. Human Reprod Update 2003;9:149-61.

9. Bohnet HG, Fielder K. Leidenberger FA. Subclinical hypothyroidism and infertility. Lancet 1981;2:1278-9.

10. Mohapatra S, Behera SK.Prevalence of hypothyroidism in patients with provisional diagnosis of DUB. IJOG 2017;3(1):23-29.

11. Parveen M, Kumari S, Haque SS, Kumar R. Evaluation of thyroid profile status in women with abnormal uterine bleeding in north Indian population. Int $J$ of Biomed Adv Res 2017;8(7):288-91.

12. Ali J, Das KK, Konyak P. Study of Relation of Thyroid Profile with Abnormal Uterine Bleeding. Sch J App Med Sci 2015;3(7D):2688-2692.

13. Jinger SK, Verma A, Dayma I, Talreja T. To study the thyroid profile in menstrual disorder at tertiary care hospital in northern western Rajasthan, India. Int J Res Med Sci 2017;5(5):2212-14.

14. George L, Jacob KJ, Shankar SB. The role of thyroid hormone status in abnormal uterine bleeding. J Evol Med Dent Sci 2017;6(76):5448-51.

15. Verma SK, Pal A, Jaswal S. A study of thyroid dysfunction in dysfunctional uterine bleeding. Int J Reprod Contracept Obstet Gynecol 2017;6(5):2035-39.

16. Maria JD, Jayakumari S, Sundaram PS. A Prospective study on Hypothyroidism in Premenopausal women. Int J pharm Sci Rev Res 2016;39(1):183-7.

17. Avasthi S, Das A. Thyroid Dysfunction in patients with menstrual disorders a study in Eastern Odisha. Global J Res Anal 2018;7(2):31. 
18. Deshmukh PY, Boricha BG, Pandey A. The association of thyroid disorders with abnormal uterine bleeding. Int J Reprod Contracept Obstet Gynecol 2015;4(3):701-8.

How to cite this article: Verma $\mathrm{K}$, Verma S, Rajoria L, A cross sectional study to evaluate the relation between thyroid disorders and abnormal uterine bleeding in reproductive age group. Indian J Obstet Gynecol Res 2019;6(2):177-180. 